\title{
COVID-19 Coronavirus: Is Infection along with Mycoplasma or Other Bacteria Linked to Progression to a Lethal Outcome?
}

\author{
Garth L. Nicolson ${ }^{1}$, Gonzalo Ferreira de Mattos ${ }^{2}$ \\ ${ }^{1}$ Department of Molecular Pathology, The Institute for Molecular Medicine, Huntington Beach, USA \\ ${ }^{2}$ Laboratory of Ion Channels, Biological Membranes and Cell Signaling, Department of Biophysics, Facultad de Medicina, \\ Universidad de la República, Montevideo, Uruguay \\ Email: *gnicolson@immed.org
}

How to cite this paper: Nicolson, G.L. and de Mattos, G.F. (2020) COVID-19 Coronavirus: Is Infection along with Mycoplasma or Other Bacteria Linked to Progression to a Lethal Outcome? International Journal of Clinical Medicine, 11, 282-302.

https://doi.org/10.4236/ijcm.2020.115029

Received: April 29, 2020

Accepted: May 17, 2020

Published: May 20, 2020

Copyright () 2020 by author(s) and Scientific Research Publishing Inc. This work is licensed under the Creative Commons Attribution International License (CC BY 4.0).

http://creativecommons.org/licenses/by/4.0/ (c) (i) Open Access

\begin{abstract}
Most patients with COVID-19 disease caused by the SARS-CoV-2 virus recover from this infection, but a significant fraction progress to a fatal outcome. As with some other RNA viruses, co-infection or activation of latent bacterial infections along with pre-existing health conditions in COVID-19 disease may be important in determining a fatal disease course. Mycoplasma spp. ( $M$. pneumonaie, $M$. fermentans, etc.) have been routinely found as co-infections in a wide number of clinical conditions, and in some cases this has progressed to a fatal disease. Although preliminary, Mycoplasma pneumoniae has been identified in COVID-19 disease, and the severity of some signs and symptoms in progressive COVID-19 patients could be due, in part, to Mycoplasma or other bacterial infections. Moreover, the presence of pathogenic Mycoplasma species or other pathogenic bacteria in COVID-19 disease may confer a perfect storm of cytokine and hemodynamic dysfunction, autoimmune activation, mitochondrial dysfunction and other complications that together cannot be easily corrected in patients with pre-existing health conditions. The positive responses of only some COVID-19 patients to antibiotic and anti-malaria therapy could have been the result of suppression of Mycoplasma species and other bacterial co-infections in subsets of patients. Thus it may be useful to use molecular tests to determine the presence of pathogenic Mycoplasma species and other pathogenic bacteria that are commonly found in atypical pneumonia in all hospitalized COVID-19 patients, and when positive results are obtained, these patients should treated accordingly in order to improve clinical responses and patient outcomes.
\end{abstract}

\section{Keywords}

Pathogenic Mycoplasma, SARS-CoV-2 Virus, COVID-19 Disease, Acute 
Respiratory Distress Syndrome, Co-Infection, Pneumonia, Lethal Infection, Mitochondria, Cytokines, Anti-Microbial Therapy, Antibiotics, Anti-Malarial Therapy, Virus, Bacteria

\section{Introduction}

The appearance of an outbreak of unexplainable pneumonia in Hubei province, China in 2019 revealed that a new coronavirus named 2019-nCoV (renamed SARS-CoV-2 coronavirus) was the cause [1] [2]. Patients presented with respiratory and other symptoms, such as cough, fever, and lung damage, along with fatigue, myalgia, dyspnoea, arthralgia, diarrhea, vomiting, headache, among other symptoms [2] [3].

Outcomes of COVID-19 vary from mild, self-limiting disease with respiratory symptoms to more severe manifestations and death [3] [4]. Patients with COVID19 that progressed to death generally were older and had other underlying health conditions, such as hypertension, cardiovascular disease, chronic obstructive pulmonary disease, diabetes, chronic kidney disease, malignancy, or other conditions [4] [5]. The severe complications associated with non-survival from COVID-19 were primarily acute respiratory distress syndrome (ARDS), septic shock, metabolic acidosis, coagulation dysfunction and multiple organ failure [5] [6] [7]. Among the most common organ failures were lung, heart and kidney [7]. Rarely mentioned in these articles was the possibility that other bacterial or viral coinfections could be contributing to either the pathogenesis of SARS-CoV-2 or to the lethal phase of the disease.

This contribution will focus on a possible role for intracellular bacterial infections, such as Mycoplasma species and other possible intracellular bacteria (Chlamydia pneumoniae, among other possible infections), in the progression and non-survival of COVID-19 patients. Such infections, if present, could contribute to the lethality of the SARS-CoV-2 virus in COVID-19 patients.

\section{Mycoplasma Species}

One of the most commonly found co-infections in a variety of chronic health conditions and diseases are various pathogenic Mycoplasma species [8] [9] [10]. Pathogenic Mycoplasma species infections are usually community-acquired infections that are non-fatal, but some patients can progress to a fulminant, systemic disease that results in death [11] [12].

Mycoplasmal infections are often associated with other bacterial and viral infections [8] [9] [10] [13] [14] [15], and the presence of multiple Mycoplasma species (and other bacteria and viruses) has been statistically associated with more severe signs and symptoms in chronic illnesses [14]. An example is tickborne Lyme disease where several co-infections are involved in causing complex clinical presentations, and in this example Mycoplasma was usually the most 
common Lyme disease co-infection found with Borrelia species and other infections [15] [16]. Also, mycoplasma infections are often found in community-acquired pneumonia as co-infections with influenza and other infections [17] [18] [19] [20] [21]. Co-infections of mycoplasma have been found previously in patients with SARS virus infections [22].

Pathogenic mycoplasmas are often found as respiratory tract infections that induce airway inflammation and bronchial hyper-responsiveness (BHR) [23]. For example, the induction of M. pneumoniae-specific IgE and IgA is likely to play an important role in exacerbating BHR and asthma. Indeed, elevations of IgE antibodies specific to $M$. pneumoniae have been detected in the serum of patients with M. pneumoniae-induced pneumonia. The serum levels of specific IgE and IgA followed infection with $M$. pneumoniae, and this was especially true in patients with pre-existing asthma-BHR [24]. M. pneumoniae was found in $24.7 \%$ of patients with asthma-BHR but in only 5.7\% of control subjects [25].

Mycoplasma pneumoniae has recently been identified in COVID-19 disease [26]. This communication [26], along with a different case report [27], suggested that Mycoplasma should be considered as a possible co-infection in progressive COVID-19 disease. In a separate study with 138 patients with COVID-19, 26.5\% of COVID-19 patients were found to have Mycoplasma species infections [28]. This percentage may be low due to the insensitivity of the testing procedures used [28]. Other related bacteria, such as Chlamydia pneumoniae and other Chlamydia species were also found at similar levels, but it was not clear from this contribution whether this occurred in the same patients that were positive for mycoplasma or in different patients [28]. COVID-19 patients are rarely examined for intracellular bacterial infections like mycoplasma [2] [3] [4] [5] [6]. In the cases where bacterial infections have been considered, Klebsiella pneumoniae, Aspergillus flavus, A. fumigatus, extended spectrum $\beta$-lactamase-positive (ESBL) K. pneumoniae, ESBL-positive Pseudomonas aeruginosa, and ESBLnegative Serratia marcescens, and Candida albicans have been found, usually in individual patients. When these bacterial infections were found in COVID-19 patients, they were considered hospital-acquired and unrelated to patient mortality [7].

\section{Oxygen Deprivation and Mitochondria}

The usual clinical course for patients with fatal COVID-19 disease has been found to be progression to critical ARDS requiring oxygen and mechanical ventilation [1] [2] [3] [7]. In the severe cases of SARS-CoV-2 infections the most significant difference between surviving patients and non-surviving patients was the ratio of partial pressure of oxygen $\left(\mathrm{PaO}_{2}\right)$ to fraction of inspired oxygen $\left(\mathrm{FiO}_{2}\right.$, from arterial blood gas analysis)or acute onset hypoxemia [7]. The ratios of $\mathrm{PaO}_{2}$ to $\mathrm{FiO}_{2}$ were found to be significantly lower in non-survivors, consistent with severe ARDS [7] [29]. Even with extracorporeal membrane oxygenation [7] or inhaled pulmonary vasodilators [20], critical COVID-19 patients failed to survive. 
This suggests that oxygen is not being taken in, utilized effectively and passed into the circulation by lung tissues, possibly because cells infected with SARSCoV-2 virus and other intracellular bacterial co-infections have lost their abilities to maintain proper cellular and circulatory oxygen levels.

In cells oxygen is utilized by mitochondria to produce high-energy molecules through oxidative phosphorylation. Mitochondria are also required for other critical functions, such as regulation of ion and redox homeostasis, biosynthesis of lipid and other metabolites, innate immunity, autophagy, cell signaling, regulation of cell death, and other cellular functions [30] [31]. Mitochondria can be affected negatively by several types of infections, including coronaviruses (see below) and mycoplasmas [32] [33] [34] [35]. For example, Mycoplasma pneumoniae infection results in the excess production of Reactive Oxygen Species (ROS) that can damage mitochondrial membranes and mitochondrial DNA. ROS have also been found to interfere with mitochondrial metabolism and stress responses in human lung cells [35]. Infections like mycoplasma also steal important mitochondrial metabolites that are needed for mitochondrial function and produce toxic molecules that damage mitochondria and cells and affect mitochondrial function (see below).

In COVID-19 patients compromised oxygen exchange in the air sacs of the lungs could be the cause of dyspnea or hypoxia [36]. However, the problem is likely to be more systemic, involving widespread mitochondrial dysfunction in endothelial cells and in various tissues and organs affected by SARS-CoV-2 and other co-infections. Possible co-infections include various mycoplasmas and other intracellular bacteria that can cause mitochondrial dysfunction [32]-[37]. In addition to lungs, organ damage can also occur in other tissues, such as heart and kidney, and cause their failure [2] [3] [7].

\section{Suppression of Host and Mitochondrial Responses}

Mitochondria have an impact on the pathogenesis of many common diseases and disorders, including neurodegenerative diseases, metabolic diseases, cardiovascular diseases, fatiguing illnesses, among others, and importantly for this discussion, infectious diseases [31] [32] [33] [37] [38]. Some infections alter mitochondrial dynamics and promote pathogenesis that benefits the infectious process [33]. For example, SARS coronaviruses interfere with mitochondrial mitophagy and innate immunity against infections [34]. This will be discussed in more detail in the next section.

In acute COVID-19 cases with severe respiratory complications (ARDS) the patients who died had severe massive alveolar damage and progressive respiratory failure [7] [36], even in cases where antiviral and corticosteroid therapies were given in an effort to attenuate pulmonary inflammation [36]. Lymphocytopenia has been a common finding in COVID-19 patients [29], but this finding has not been useful in identifying whether a patient will survive or not [7]. When mononuclear cells were examined in COVID-19 patients, their status was 
concluded to be hyper-activated, with high proportions of CD4, CD8 and CD38 cells, increased numbers of proinflammatory cells, and high concentrations of cytotoxic granules inside cells [36].

Pathogenic mycoplasmas, such as M. pneumoniae, are known to cause community-acquired atypical pneumonias with immunological manifestations [12] [24] [39]. These infections are typified by inflammatory reactions and immune suppression [12] [24] [40] [41] [42]. However, mycoplasmas do not possess typical bacterial cell walls that contain inflammation-inducing endotoxins, such as lipopolysaccharides [12] [41]. Instead, mycoplasmas contain lipoproteins that can induce inflammatory responses through Toll-like (TLR) and other receptors, and they induce release of pro-inflammatory cytokines that contribute to the clinical problem [41] [42] [43]. This will be discussed further in Section 7.

Since the populous has not been exposed previously to the SARS-CoV-2 virus, they generally do not possess immunity to this infection and thus adaptive immune responses are non-existent [44]. However, based on findings with other coronaviruses, such as SARS-CoV, host innate immune response systems that utilize pattern recognition and TLR receptors will likely be involved in initial responses [45]. Even when the adaptive immune responses are initiated, involving various $\mathrm{T}$ cell linages and $\mathrm{B}$ cell production of antibodies, SARS-CoV-2 may initiate immune suppression by inducing apoptosis of $\mathrm{T}$ cells. This type of B-cell humoral immunity is thought to be important in combating infections of SARS-CoV-2 [44].

\section{Blood and Coagulation Disturbances}

Patients with COVID-19 disease and atypical pneumonia tend to show blood disturbances, such as leukoctyopenia, lymphocytopenia and thrombocytopenia, along with elevated levels of aspartate aminotransferase, alanine aminotransferase, creatine kinase and troponin 1 that were related to severity of disease [2] [7] [46]. These latter serum markers are indicative of liver, kidney and heart injury and are consistent with clinical findings on COVID-19 [2] [7] [44] [46].

Increased levels of C-reactive protein and erythrocyte sedimentation were also routinely found, suggesting endothelial cell damage in COVID-19 disease [44] [46] [47]. The COVID-19 patients requiring intensive care (ICU) also showed significant differences in prothrombin clotting time and increases in the presence of D-dimers (fibrin degradation fragments) [2]. There were differences also between surviving and non-surviving COVID-19 patients in ICUs [48]. Thrombotic complications have been a common finding in COVID-19 patients, with increases in acute pulmonary embolism, deep-vein thrombosis and systemic arterial embolism, despite intensive thromboprophylaxis [49]. It has been especially important to control blood hemodynamics in COVID-19 patients, especially in those patients requiring ventilation [47] [48] [49].

Similar to COVID-19 disease, patients with mycoplasma infections, especially M. pneumoniae infections, show significant increases in serum aspartate amino- 
transferase, alanine aminotransferase as well as increases in lactate dehydrogenase [50]. As found in COVID-19 disease, this suggests that organ damage to liver and possibly other organs by the infectious process could be enhanced by the presence of mycoplasma or other bacteria. Also, high levels of C-reactive protein are typical in $M$. pneumoniae infections, and the ratios of C-reactive protein to procalcitonin were found to be predictive for mycoplasma-induced pneumonia [51]. Similar to COVID-19 patients, common findings in M. pneumoniae infections are thrombocytopenia, widespread platelet aggregation and hemolytic anemia [52].

\section{Biotoxins and Host Responses}

Various infective agents have evolved with different strategies to evade host nonimmune and immune mechanisms that have been developed to inhibit infections. Simple RNA viruses use explosive replication to outpace host response mechanisms, but they have also evolved with particular strategies to deal with host responses, such as innate host responses and adaptive immune responses. SARS-CoV virus components or their replication intermediates are first recognized by host innate response systems using Pattern Recognition Receptors (PRRs) present in the cytosol and on various cellular membranes. These PRRs recognize viral Pathogen Associated Molecular Patterns (PAMPs) or viral structures with unique structural characteristics and initiate anti-infective responses [53] [54].

While SARS-CoV viruses attempt to evade host innate recognition and response systems, host cells that detect SARS-CoV viruses turn on production of cytokines, chemokines and interferon-stimulated gene (ISG)responses to counter SARS-CoV infections [54] [55]. This will be considered in the context of fatal infections in the next section. To counter innate immune signaling, SARS-CoV viruses encode several proteins that antagonize the host response to prevent activation of antiviral systems inside host cells and prevent host interferon responses [54].

Mycoplasmas use various virulence mechanisms to survive during their pathogenic development [56] [57]. Inside cells they compete for cellular nutrients and metabolites, and in this way they can depletehost precursor molecules and disrupthost metabolic and synthetic pathways [56]. They also secrete some of their own enzymes, such as lipases, proteases, nucleases and other enzymes, that can disrupt and interfere with host structures and metabolites [57] [58]. Mycoplasmas can also stimulate the generation of hydrogen peroxide and superoxide radicals that damage host cellular membranes, mitochondria and other structures [56].

Pathogenic mycoplasmas can synthesize degradative enzymes that can damage tissues and cause pathogenic changes, such as secondary necrosis [59]. They can also cause tissue damage with the morphological characteristics of apoptosis, such as chromatin condensation, as well as necrosis, with characteristic loss of 
membrane integrity and organelle swelling [60]. Arginine deaminase is an example of a growth-inhibitory mycoplasma-produced enzyme that inhibits the growth of human T-cells. This enzyme can suppresses IL-2 production and receptor expression in T-cells stimulated by non-specific mitogens. It can also produce the morphologic features of dying cells, such as DNA fragmentation that is seen during apoptosis [42]. This enzyme has been followed in patients with community-acquired pneumonia as a possible marker for $M$. pneumoniae infections [61].

Some Mycoplasma species can directly cause host cell death, but a more common feature of pathogenic mycoplasma infections is the induction of host cytokines [62]. Indeed, cytokine-inducing activity is a general feature of most, if not all, pathogenic Mycoplasma species, and this important topic for COVID-19 disease will be discussed in the next section. The cell death effects of mycoplasmas are usually mediated by lipid-associated molecules (lipoproteins), and they are not associated with decreases in mitochondrial trans-membrane potential or inhibited by pre-incubation with the drug $\mathrm{N}$-acetylcysteine, which is typically found in TNF $\alpha$-mediated apoptosis. Rather, a non-lipid-associated protein (15 $30 \mathrm{kDa}$ ) was found to cause mycoplasma-mediated cell death [63].

Similar to SARS-CoV viruses, pathogenic mycoplasmas cause cardiovascular and pulmonary manifestations that can result in extreme patient morbidity and death [57] [61] [62]. Several examples of cardiovascular and pulmonary tissue damage have been reported as due to vascular occlusion via thrombosis and the formation of vascular immune complexes. Pathogenic mycoplasma-caused vascular occlusion has been reported for heart, lung, kidney, brain and other organs [60] [62].

Pathogenic mycoplasmas also release biotoxins that directly damage cells and tissues and stimulate host innate response systems [58] [62] [63] [64]. A Mycoplasma pneumoniae-released biotoxin, called the community-acquired respiratory distress syndrome toxin (CARDS), has been isolated and found to bean ADPand protein-ribosylating as well as a vacuole-causing cytotoxin [65]. The effects of this biotoxin also include alterations of enzymes and other proteins of various metabolic pathways. As mentioned above, this biotoxin activates innate immunity, and this is mediated through the NLRP3 inflammasome complex, which ultimately causes cell-release of IL-1. It also stimulates hyper-inflammation and tissue damage, among other pathologic effects, and it appears to be responsible, in part, for pulmonary inflammation along with cytokine release. Clinically it causes significant airway dysfunction, which is usually seen as loss of ciliary function of the respiratory epithelium and includes lung cell vacuolization, lung cell rounding/distortion and disruption of pulmonary epithelial integrity. It may be responsible for respiratory failure and some of the fatal outcomes that have been found in acute $M$. pneumoniae infections [66].

\section{Cytokines and Cytokine Storms}

Excess inflammatory cytokine and chemokine production and release into the 
surrounding tissue and the circulatory system ("cytokine storm") can be seen during severe infectious disease progression, and it is often found in fatal cases of viral infections. It is caused by a severe and excessive immune response initiated by a positive feedback cycle between various cytokines and immune cells.

COVID-19 disease progression to severe hypoxia, pulmonary edema, accumulation of inflammatory cells in the lungs, ARDS and eventually organ failure often ends in a lethal outcome with high mortality rates [2] [3] [5] [6] [7]. Consistent with this lethal progression is the increasing induction and production of inflammatory cytokines, including interleukin-1 (IL-1), IL-6, IL-7, IL-8, IL-10, tumor necrosis factor-alpha (TNF $\alpha$ ) and other cytokines and chemokines, all of which have been found in SARS-CoV viral infections [54] [55]. Compared to healthy, non-symptomatic adults the levels of plasma cytokines (IL-1 $\beta$, IL-RA, IL-7, IL-8, IL-9, IL-10, TNF $\alpha$ and other cytokines and chemokines) were higher in both non-ICU and ICU patients with COVID-19 disease compared to controls [2]. Importantly, recent studies have shown significantly higher levels of inflammatory cytokines (IL-2R, IL-6, IL-8, IL-10, TNF $\alpha$ ) in ICU non-survivors compared to ICU survivors of COVID-19 disease [67]. This suggests that excessive, multiple cytokines produced during progressive disease or 'cytokine storm' contributes to the fatal outcome seen in many COVID-19 patients.

Cytokine/chemokine release at tissue sites, such as the inflammatory cytokines and chemokines found at exaggerated levels in lung tissue during RNA virus infections, is particularly difficult to deal with in animals and in humans [68] [69]. There are over 150 different pro-inflammatory and anti-inflammatory cytokines, chemokines, interferons, growth factors and other tissue factors that are synthesized and released into tissues and the blood during a vigorous immune system response, and these signaling molecules can cause high fever, redness, swelling, fatigue, nausea and other symptoms [68] [69] [70].

At the cellular and tissue levels SARS-CoV viruses and the virus-induced cytokine storms that are caused by these viruses result in significant damage to tissues, especially lung tissue. This pulmonary damage can be observed as diffuse injury to alveolar epithelial cells, fibroblasts and alveolar macrophages. Specifically, the damage has been characterized as hyaline membrane formation, desquamation of pneumocytes, edema and inflammatory cell infiltration, among other adverse effects [71].

During the infection process lung cells secrete various cytokines and chemokines that induce fibroblast activation, extracellular matrix deposition and alveolar epithelial damage. Such aberrant response, along with excessive cytokine production, are not unique to RNA viruses; they have been associated with the pathogenesis of a variety of non-infectious and infectious diseases, from viral infections to neurodegenerative disorders [70].

Mycoplasma infections also result in the production of inflammatory cytokines, including IL- $1 \beta$, IL-2, IL-6, IL-8 and TNF $\alpha$ as well as various interferons and leukocyte growth factors [57] [62] [63] [64]. In fatal cases of $M$. pneumoniae 
cytokines, such as IL-18 but not interferon, were found to be significantly higher in, for example, patients with fulminant pneumonia [12]. During infection by $M$. pneumonia the production of cytokines (IL- $1 \beta$, IL-6, IL-10, TNF $\alpha$, among others) increases markedly, and this is thought to be an indication of tissue damage [72]. In the case of $M$. pneumoniae such damage has been directly related to the release of various inflammatory cytokines, chemokines and other inflammatory molecules and the subsequent tissue and immune responses to these molecules [72].

\section{Antibiotics, Anti-Malarial and Other Treatments}

In describing some of the treatments used to fight COVID-19 disease, we will only discuss here those commonly used treatments that relate to possible bacterial co-infections or activated latent bacterial infections. Although the consequences of SARS-CoV-2 coronavirus anti-viral and other treatments and general ICU supportive procedures are fundamentally important in caring for COVID19 patients, that is not the purpose of our contribution. The use of anti-viral and other drugs and ICU supportive procedures have been extensively reviewed by others, and this discussion will not be repeated here. Thus the reader is referred to other recent articles for information on primary and ICU supportive treatments useful in the management of COVID-19 disease [2] [6] [7] [28] [29] [44] [47] [48].

\subsection{Antibiotics and COVID-19}

Since mycoplasmas do not have cell walls, the antibiotics that act on cell wall synthesis, such as $\beta$-lactams (penicillins, cephalosporins, among others),are ineffective against mycoplasmas [24] [62] [64] [73] [74]. Thus mycoplasmas are often treated with anti-microbials that act on their metabolism, replication, synthetic machinery or other specific bacterial targets, even though the actions of these drugs are mainly bacterostatic [24] [62] [74]. Since most mycoplasmas are sensitive to tetracyclines (doxycycline, minocycline, among others) or macrolides (azithromycin, clarithromycin, among others), with some notable exceptions [62] [75] [76] [77], these are often used for frontline treatment of Mycoplasma species, and quinolones (ciprofloxacin, sparfloxacin, levofloxacin, among others), are often used as alternative treatments [62] [76].

In general viruses are not susceptible to antibiotics, but particular antibiotics have been used during viral infections to treat bacterial co-infections or latent infections. This is common in cases of adult community-acquired pneumonia where Mycoplasma species were often the most frequent type of bacterial infection found in cases identified as viral pneumonia [78].

In addition, some macrolide antibiotics, such as azithromycin, have anti-viral activities against specific viruses, such as rhinoviruses identified in virus-associated pulmonary conditions found in cystic fibrosis [79] and zika virus recovered from developing human brain tissue [80]. In bronchial epithelial cells pre- 
treatment with azithromycin reduced rhinovirus replication as well as asthma exacerbations and other complications, as estimated by the synthesis of proinflammatory cytokines, interferon- $\beta$ responses and increases in rhinovirus-induced pattern recognition receptor [79].

Other macrolides may be useful in the treatment of respiratory viral infections due to their effects on pulmonary cells. In this situation the positive effects of macrolides have been attributed, in part, to their anti-inflammatory and immunomodulatory effects [81] [82] [83]. Although macrolides have been shown to be efficacious in treating some infections, their use comes with some possible risk of cardiac complications, such as QT prolongation [84].

In COVID-19 disease antibiotics have been used mainly as a part of supportive care and prevention of super-infection, without identification of possible bacterial co-infections or activation of latent bacterial infections [2] [7] [44] [47] [48]. In some treatment studies on COVID-19 disease an antibiotic (azithromycin) was used with an anti-malarial drug (hydroxychloroquine). For example, this combination was used in Marseille, France in an open label non-randomized clinical trial, but the azithromycin was added mainly as a part of supportive care [85]. The results of this preliminary study will be discussed in the next section.

Another antibiotic active against mycoplasmas, doxycycline [62] [64] [73], might also be useful in COVID-19 because of its potential binding to rRNA and inhibition of microbial protein synthesis [86]. Indeed, doxycycline has proved to be an important option for chronic mycoplasma infections resistant to other treatments [62] [73], and its effectiveness in COVID-19 care might be more related to its suppression of bacterial growth than any anti-viral action.

\subsection{Anti-Malarial Drugs and COVID-19}

The interesting use of the anti-malarial drug, hydroxychloroquine, in the treatment of COVID-19 disease was reported by Gautret et al. [85]. This followed from an earlier study on the suppressive effects of chloroquine on SARS-CoV infection of Vero E6 cells in culture [87]. Chloroquine and hydroxychloroquine have many uses because of their anti-inflammatory and potential chemo-sensitization properties; they have been used widely to treat various human diseases, such as malaria and amoebiosis, without significant adverse effects [88]. The main anti-parasitic and anti-viral effects of the chloroquines are thought to occur by the alkylization of cellular endosomes, Golgi and lysosomes, and possibly also by affecting phospholipid metabolism and zinc ion levels to modify parasite and virus entry [89]. In addition, chloroquines block BK channels that are essential in proinflammatory responses that can lead to cytokine storms [90].

In China chloroquine phosphate has been used to treat COVID-19 pneumonia patients. Although a recent preliminary report on this lacks detail and analysis, it was stated that chloroquine could be a breakthrough in COVID-19 treatment [91]. In this study, patients receiving chloroquine phosphate showed less exacerbation of pneumonia, and they had improved lung imaging compared to 
control treatment. In addition, severe adverse reactions to chloroquine phosphate were not found in these patients [91]. In the French study using hydroxychloroquine and azithromycin, viral carriage was reduced significantly over a 6-day study with hydroxychloroquine, and the addition of azithromycin was significantly better than hydroxychloroquine alone [85]. In a recent randomized clinical trial using low (450 mg) and high (600 $\mathrm{mg}$ ) dose chloroquine as adjunct therapy for COVID-19 patients viral RNA was detected at about the same prevalence in both groups: $31 / 41$ (low dose) and 31/40 (high dose). However, by day 13 fatalities in the high-dose group were higher (39\%) than in the low-dose group (15\%), most likely because of a higher incidence of heart problems in the high-dose group [92]. Thus use of chloroquine or hydroxychloroquine for COVID19 disease may come at a cost-a higher incidence of coronary problems [92]. Even with these limitations, hydroxychloroquine and chloroquine phosphate have been proposed to be potentially useful experimental drugs for the treatment of some COVID-19 patients [93].

\subsection{Other Treatments in COVID-19}

In addition to anti-viral drugs that target SARS-CoV-2 viral replication, other treatment approaches for COVID-19 disease include methods to inhibit viral attachment, fusion and entry into cells, suppression of inflammatory responses, vaccines and convalescent plasma treatments [94] as well as combinations of conventional and alternative medicine [37] [38] [94]. For example, various combinations of anti-viral, anti-inflammatory and other drugs along with anti-oxidants, zinc ion, and other approaches, such as the use of molecular hydrogen to help control inflammation and oxidative damage, have been proposed [95]. For the most part, the current approaches used to develop new treatments for COVID-19 disease do not take into account the possibility of bacterial co-infections or activation of latent bacterial infections.

\section{Final Comments}

Our hypothesis has been that infections like Mycoplasma and other bacterial species (Chlamydia pneumoniae, among others) could be contributing to the morbidity and mortality seen in COVID-19 disease. Infections like M. pneumoniae, $M$. fermentans and other Mycoplasma species are known to cause lethal diseases on their own in some patients, so when present with SARS-CoV-2 infections, they could be significantly contributing to COVID-19 mortality. In other diseases caused by RNA viruses, such as HIV-1, M. fermentans and $M$. penetrans co-infections have been proposed to be important co-factors in the development of fatal disease [96] [97]. This could also be, in part, the reason that some patients with COVID-19 progress to a fatal disease.

Mycoplasma and other similar bacterial infections should be carefully analyzed in critical COVID-19 patients. If such tests are positive, these patients should be treated accordingly [62] [64] [73]. In order to determine the possible 
role of Mycoplasma species in the progression of COVID-19 disease to a fatal disease course, patients who are positive for such infections should be compared to patients that do not have these infections at various stages of the disease process to see if the SARS-CoV-2 virus can activate latent Mycoplasma species or enhance sub-clinical mycoplasma infections and promote COVID-19 disease morbidity and progression to a fatal outcome.

\section{Note Added in Proof}

Since we prepared this manuscript, there have been recent contributions, mostly brief preprint reports or letters that support our hypothesis. Charkraborty and Das [98] discussed the possibility that anaerobic bacteria, including Mycoplasma species, could be causing secondary infections in COVID-19 disease. They have proposed that such infections may be altering hemoglobin degradation and producing metabolites that affect hypoxia in progressing COVID-19 patients [98]. Stricker and Fesler [99] suggested that patients who have COVID-19 disease should not progress to a fatal outcome, if their therapy includes combinations of antibiotics (including minocycline or doxycycline) used for tick-borne infections [99]. As we discussed previously, Lyme disease patients often have mycoplasma co-infections that are sensitive to minocycline and doxycycline [62] [75].

\section{Acknowledgements}

We would like to thank former and present colleagues for their intellectual support. This contribution was supported by internal funds from the Department of Molecular Pathology, The Institute for Molecular Medicine and the Department of Ion Channels, Biological Membranes and Cell Signaling, Department of Biophysics, Facultad de Medicina, Universidad de la República.

\section{Disclosures}

One of us (G.L.N.) is a part-time consultant to Nutritional Therapeutics, Inc., Naturally plus USA and UNVIA Naturally plus Taiwan.

\section{Conflicts of Interest}

The authors have no conflicts of interest to declare regarding this contribution.

\section{References}

[1] Burki, T.K. (2020) Coronavirus in China. Lancet Respiratory Medicine, 8, 238. https://doi.org/10.1016/S2213-2600(20)30056-4

[2] Huang, C., Wang, Y., Li, X., Ren, I., Zhao, J., Hu, Y., et al. (2020) Clinical Features of Patients Infected with 2019 Novel Coronavirus in Wuhan, China. The Lancet, 395, 497-506. https://doi.org/10.1016/S0140-6736(20)30183-5

https://www.thelancet.com/journals/thelancet/article/PIIS0140-6736(20)30183-5/ful $\underline{\text { ltext }}$

[3] Li, J.-Y., You, Z., Wang, Q., Zhou, Z.-J., Qiu, Y., Luo, R. and Ge, X.-Y. (2020) The 
Epidemic of 2019-Novel-Coronavirus (2019-nCov) Pneumonia and Insights for Emerging Infectious Diseases in the Future. Microbes and Infections, 22, 80-85. https://www.sciencedirect.com/science/article/pii/S1286457920300307 https://doi.org/10.1016/j.micinf.2020.02.002

[4] Chen, J. (2020) Pathogenicity and Transmissibility of 2019-nCov-A Quick Overview and Comparison with Other Re-Emerging Viruses. Microbes and Infections, 22, 69-71. https://www.sciencedirect.com/science/article/pii/S1286457920300265 https://doi.org/10.1016/j.micinf.2020.01.004

[5] Emami, A., Javanmardi, F., Pirbonyeh, N. and Akbari, A. (2020) Prevalence of Underlying Diseases in Hospitalized Patients with COVID-19: A Systematic Review and Meta-Analysis. Archives of Academic Emergency Medicine, 8, e35. http://journals.sbmu.ac.ir/aaem/index.php/AAEM/article/view/600/754

[6] Guo, Y.-R., Cao, Q.-D., Hong, Z.-S., Tan, Y.-Y., Chen, S.-D., Jin, H.-J., Tan, K.-S., Wang, D.-Y. and Yan, Y. (2020) The Origin, Transmission and Clinical Therapies on Coronavirus Disease 2019 (COVID-19) Outbreak-An Update on the Status. Military Medical Research, 7, Article No. 11. https://doi.org/10.1186/s40779-020-00240-0

[7] Yang, X., Yu, Y., Xu, J., Shu, H., Xia, J., et al. (2020) Clinical Course and Outcomes of Critically Ill Patients with SARS-CoV-2 Pneumonia in Wuhan, China: A Single-Centered, Retrospective, Observational Study. The Lancet Respiratory Medicine, 8, e26. https://www.ncbi.nlm.nih.gov/pmc/articles/PMC7102538 https://doi.org/10.1016/S2213-2600(20)30079-5

[8] Nicolson, G.L. (2008) Chronic Infections in Neurodegenerative and Neurobehavioral Diseases. Lab Medicine, 39, 291-299.

https://academic.oup.com/labmed/article/39/5/291/2504709 https://doi.org/10.1309/96M3BWYP42L11BFU

[9] Nicolson, G.L. and Haier, J. (2009) Role of Chronic Bacterial and Viral Infections in Neurodegenerative, Neurobehavioral, Psychiatric, Autoimmune and Fatiguing Illnesses: Part 1. British Journal of Medical Practitioners, 2, 20-28.

https://www.bjmp.org/content/role-chronic-bacterial-and-viral-infections-neurode generative-neurobehavioral-psychiatric-au

[10] Nicolson, G.L. and Haier, J. (2010) Role of Chronic Bacterial and Viral Infections in Neurodegenerative, Neurobehavioral, Psychiatric, Autoimmune and Fatiguing Illnesses: Part 2. British Journal of Medical Practitioners, 3, e301.

https://www.bjmp.org/content/role-chronic-bacterial-and-viral-infections-neurode generative-neurobehavioural-psychiatric-a

[11] Lo, S.-C., Dawson, M.S., Newton, P.B., et al. (1989) Association of the Virus-Like Infectious Agent Originally Reported in Patients with AIDS with Acute Fatal Disease in Previously Healthy Non-AIDS Patients. American Journal of Tropical Medicine and Hygiene, 41, 364-376. https://doi.org/10.4269/ajtmh.1989.41.364 https://www.ajtmh.org/content/journals/10.4269/ajtmh.1989.41.364

[12] Izumikawa, K. (2016) Clinical Features of Severe or Fatal Mycoplasma pneumoniae Pneumonia. Frontiers in Microbiology, 7, Article No. 800. https://www.frontiersin.org/articles/10.3389/fmicb.2016.00800/full https://doi.org/10.3389/fmicb.2016.00800

[13] Nicolson, G.L., Gan, R., Nicolson, N.L. and Haier, J. (2007) Evidence for Mycoplasma, Chlamydia pneunomiae and HHV-6 Co-Infections in the Blood of Patients with Autistic Spectrum Disorders. Journal of Neuroscience Research, 85, 1143-1148. https://doi.org/10.1002/jnr.21203

[14] Nicolson, G.L., Gan, R. and Haier, J. (2003) Multiple Co-Infections (Mycoplasma, 
Chlamydia, Human Herpes Virus-6) in Blood of Chronic Fatigue Syndrome Patients: Association with Signs and Symptoms. Acta Pathologica Microbiologica Immunologica Scandanavia (APMIS), 111, 557-566.

https://doi.org/10.1034/j.1600-0463.2003.1110504.x

[15] Nicolson, G.L., Nicolson, N.L. and Haier, J. (2008) Chronic Fatigue Syndrome Patients Subsequently Diagnosed with Lyme Disease Borrelia burgdorferi: Evidence for Mycoplasma Species Co-Infections. Journal of Chronic Fatigue Syndrome, 14, 5-17. https://doi.org/10.1080/10573320802091809

[16] Berghoff, W. (2012) Chronic Lyme Disease and Co-Infections: Differential Diagnosis. Open Neurology Journal, 6, 158-178.

https://openneurologyjournal.com/VOLUME/6/PAGE/158/FULLTEXT https://doi.org/10.2174/1874205X01206010158

[17] Chiu, C.-Y., Chen, C.-J., Wong, K.-S., Tsai, M.-H., Chiu, C.-H. and Huang, Y.-C. (2015) Impact of Bacterial and Viral Coinfection on Mycoplasmal Pneumonia in Childhood Community-Acquired Pneumonia. Journal of Microbiology, Immunology and Infection, 48, 51-56. https://doi.org/10.1016/j.jmii.2013.06.006 https://www.sciencedirect.com/science/article/pii/S1684118213001102

[18] Hon, E.K.L., Ip, M., Chu, W.C.W. and Wong, W. (2012) Megapneumonia Coinfection: Pneumococcus, Mycoplasma pneumoniae, and Metaneumovirus. Case Reports in Medicine, 2012, Article ID: 310104. https://doi.org/10.1155/2012/310104 https://www.hindawi.com/journals/crim/2012/310104

[19] Kim, J.H., Kwon, J.H., Lee, J.-Y., Lee, J.S., Ryu, J.-M., Kim, S.-H., Lim, K.S. and Kim, W.Y. (2018) Clinical Features of Mycoplasma pneumoniae Coinfection and Need for Its Testing in Influenza Pneumonia Patients. Journal of Thoracic Disease, 10, 6118-6127. https://www.ncbi.nlm.nih.gov/pmc/articles/PMC6297417 https://doi.org/10.21037/jtd.2018.10.33

[20] Toikka, P., Juvén, T., Virkki, R., Leinonen, M., Mertsola, J. and Ruuskanen, O. (2000) Streptococcus pneumoniae and Mycoplasma pneumonia in CommunityAcquired Pneumonia. Archives of Disease in Childhood, 83, 413-414.

https://adc.bmj.com/content/archdischild/83/5/413.full.pdf https://doi.org/10.1136/adc.83.5.413

[21] Berrajah, L.F., Ben Slama, K.A., Khbou, I., Gargouri, S., Chtourou, A., Znazen, A., et al. (2018) Virus et Bactéries Atypiques Détectés dan les Infections Respiratoires Basses Communautaires de L'enfant Dans le Region de Sfax en Tunisie. Bulletin de la Société de Pathologie Exotique, 111, 90-98.

https://bspe.revuesonline.com/article.jsp?langue=en\&articleId=39461 https://doi.org/10.3166/bspe-2018-0024

[22] Zahariadis, G., Gooley, T.A., Ryall, P., Hutchinson, C., Latchford, M.I., Fearon, M.A. and Jamieson, F.B. (2006) Risk of Ruling out Severe Acute Respiratory Syndrome by Ruling in Another Diagnosis: Variable Incidence of Atypical Bacteria Coinfection Based on Diagnostic Assays. Canadian Respiratory Journal, 13, 17-22. https://www.ncbi.nlm.nih.gov/pmc/articles/PMC2539008 https://doi.org/10.1155/2006/862797

[23] Borak, J. and Lefkowitz, R.Y. (2016) Bronchial Hyperresponsiveness. Occupational Medicine, 66, 95-105. https://academic.oup.com/occmed/article/66/2/95/2750597 https://doi.org/10.1093/occmed/kqv158

[24] Parrott, G.L., Kinjo, T. and Fujita, J. (2016) A Compendium for Mycoplasma pneumoniae. Frontiers in Microbiology, 7, Article No. 513. https://www.ncbi.nlm.nih.gov/pmc/articles/PMC4828434/pdf/fmicb-07-00513.pdf https://doi.org/10.3389/fmicb.2016.00513 
[25] Seggev, J.S., Sedmak, G.V. and Kurup, V. (1996) Isotype-Specific Antibody Responses to Acute Mycoplasma pneumoniae Infection. Annals of Allergy, Asthma and Immunology, 77, 67-73. https://doi.org/10.1016/S1081-1206(10)63482-5 https://www.annallergy.org/article/S1081-1206(10)63482-5/pdf

[26] Lim, K.G.E., Chong, V.C.L., Chan, S.S.W., Ong, K.H. and Kuperan, P. (2020) COVID-19 and Mycoplasma pneumoniae Coinfection. American Journal of Hematology, 95, 1. https://doi.org/10.1002/ajh.25785

[27] Gao, Z., Gao, L., Chen, X. and Xu, Y. (2020) A 49-Year-Old Women Co-Infected with SARS-CoV-2 and Mycoplasma-A Case Report. Infectious Diseases. https://www.researchsquare.com/article/rs-16376/v1 https://doi.org/10.21203/rs.3.rs-16376/v1

[28] Geng, Y.-J., Wei, Z.-Y., Qian, H.-Y., Huang, J., Lodato, R. and Castriotta, R.J. (2020) Pathophysiological Characteristics and Therapeutic Approaches for Pulmonary Injury and Cardiovascular Complications of Coronavirus Disease 2019. Cardiovascular Pathology. (In Press) https://doi.org/10.1016/j.carpath.2020.107228

[29] Bhatraju, P.K., Ghassemieh, B.J., Nichols, M., Kim, R., Jerome, K.R., Nalla, A.K., et al. (2020) Covid-19 in Critically Ill Patients in the Seattle Region-Case Series. New England Journal of Medicine. https://doi.org/10.1056/NEJMoa2004500 https://www.ncbi.nlm.nih.gov/pmc/articles/PMC7143164

[30] Papa, S. (1996) Mitochondrial Oxidative Phosphorylation Changes in the Life Span. Molecular Aspects and Physiopathological Implications. Biochimica et Biophysica Acta, 1276, 87-105. https://doi.org/10.1016/0005-2728(96)00077-1 https://www.sciencedirect.com/science/article/pii/0005272896000771

[31] Bohovych, I. and Khalimonchuk, O. (2016) Sending Out an SOS: Mitochondria as a Signaling Hub. Frontiers in Cell and Developmental Biology, 4, a109.

https://www.frontiersin.org/articles/10.3389/fcell.2016.00109/full https://doi.org/10.3389/fcell.2016.00109

[32] Murphy, M.P. and Hartley, R.C. (2018) Mitochondria as a Therapeutic Target for Common Pathologies. Nature Reviews in Drug Discovery, 17, 865-886.

https://www.nature.com/articles/nrd.2018.174 https://doi.org/10.1038/nrd.2018.174

[33] Khan, M., Syed, G.H., Kim, S.-J. and Siddiqui, K. (2015) Mitochondrial Dynamics and Viral Infections: a Close Nexus. Biochimica et Biophysica Acta, 1853, 28222833. https://www.sciencedirect.com/science/article/pii/S0167488915000099 https://doi.org/10.1016/j.bbamcr.2014.12.040

[34] Shi, C.S., Qi, H.Y., Boularan, C., Huang, N.N., Abu-Asab, M., Shelhamer, J.H. and Kehrl, J.H. (2014) SARS-Coronaviruses Open Reading Frame-9b Suppresses Innate Immunity by Targeting Mitochondria and the MAVS/TRAF3/TRAF6 Signalosome. Journal of Immunology, 193, 3080-3089. https://doi.org/10.4049/jimmunol.1303196 https://www.jimmunol.org/content/jimmunol/193/6/3080.full.pdf

[35] Sun, G., Xu, X., Wang, Y., Shen, X., Chen, Z. and Yang, J. (2008) Mycoplasma pneumoniae Infection Induces Reactive Oxygen Species and DNA Damage in A549 Human Lung Carcinoma Cells. Infection and Immunity, 76, 4405-4413. https://iai.asm.org/content/iai/76/10/4405.full.pdf https://doi.org/10.1128/IAI.00575-08

[36] Xu, Z., Wang, Y., Zhang, J., Huang, L., Zhang, C., Liu, S., Zhao, P., et al. (2020) Pathological Findings of COVID-19 Associated with Acute Respiratory Distress Syndrome. The Lancet Respiratory Medicine, 8, 420-422. https://www.thelancet.com/pdfs/journals/lanres/PIIS2213-2600(20)30076-X.pdf https://doi.org/10.1016/S2213-2600(20)30076-X 
[37] Nicolson, G.L. and Ash, M.E. (2017) Membrane Lipid Replacement for Chronic Illnesses, Aging and Cancer Using Oral Glycerolphospholipid Formulations with Fructooligosaccharides to Restore Phospholipid Function in Cellular Membranes, Organelles, Cells and Tissues. Biochimica et Biophysica Acta Biomembranes, 1859, 1704-1724. https://doi.org/10.1016/j.bbamem.2017.04.013

[38] Nicolson, G.L., Settineri, R. and Ellithorpe, E. (2012) Glycophospholipid Formulation with NADH and CoQ10 Significantly Reduces Intractable Fatigue in Chronic Lyme Disease Patients: Preliminary Report. Functional Foods in Health and Disease, 2, 35-47. http://www.functionalfoodscenter.net/files/50313126.pdf https://doi.org/10.31989/ffhd.v2i3.100

[39] Marchello, C., Dale, A.P., Thai, T.N., Han, D.S. and Ebell, M.H. (2016) Prevalence of Atypical Pathogens in Patients with Cough and Community-Acquired Pneumonia: A Meta Analysis. Annals of Family Medicine, 14, 552-566.

https://www.ncbi.nlm.nih.gov/pmc/articles/PMC5389400 https://doi.org/10.1370/afm.1993

[40] Fernald, G.W. (1983) Immunologic Mechanisms Suggested in the Association of $M$. pneumoniae Infection and Extrapulmonary Disease: A Review. Yale Journal of Biology and Medicine, 56, 475-479.

[41] Shimizu, T. (2016) Inflammation-Inducing Factors of Mycoplasma pneumoniae. Frontiers in Microbiology, 7, Article No. 414. https://www.frontiersin.org/articles/10.3389/fmicb.2016.00414/full https://doi.org/10.3389/fmicb.2016.00414

[42] Simecka, J.W., Ross, S.E., Cassell, G.H. and Davis, J.K. (1993) Interactions of $M y$ coplasmas with B Cells: Antibody Production and Nonspecific Effects. Clinical Infectious Diseases, 17, S176-S182.

https://academic.oup.com/cid/article-abstract/17/Supplement_1/S176/309747?redir ectedFrom=fulltext https://doi.org/10.1093/clinids/17.Supplement_1.S176

[43] Quentmeier, H., Schmitt, E., Kirchhoff, H., Grote, W. and Muhlradt, P.F. (1990) Mycoplasma fermentans-Derived High-Molecular-Weight Material Induces Interleukin-6 Release in Cultures of Murine Macrophages and Human Monocytes. Infection and Immunity, 58, 1273-1280. https://iai.asm.org/content/58/5/1273 https://doi.org/10.1128/IAI.58.5.1273-1280.1990

[44] Yi, Y., Lagniton, P.N.P., Ye, S., Li, E. and Xu, R.-H. (2020) COVID-19: What Has Been Learned and to Be Learned about the Novel Coronavirus Disease. International Journal of Biological Sciences, 16, 1753-1766. https://www.ijbs.com/v16p1753.pdf https://doi.org/10.7150/ijbs.45134

[45] Lu, X., Pan, J., Tao, J. and Guo, D. (2011) SARS-CoV Nucleocapsid Protein Antagonizes IFN-beta Response by Targeting Initial Step of IFN-beta Induction Pathway, and Its C-Terminal Region Is Critical for the Antagonism. Virus Genes, 42, 37-45. https://link.springer.com/article/10.1007/s11262-010-0544-x https://doi.org/10.1007/s11262-010-0544-x

[46] Guan, W.-J., Ni, Z.-Y., Hu, Y., Liang, W.-H., Ou, C.-Q., He, J.-X., et al. (2020) Clinical Characteristics of Coronavirus Disease 2019 in China. New England Journal of Medicine. https://doi.org/10.1056/NEJMoa2002032

[47] Chen, N., Zhou, M., Dong, X., Qu, J., Gong, F., Han, Y., Qui, Y., et al. (2020) Epidemiological and Clinical Characteristics of 99 Cases of 2019 Novel Coronavirus Pneumonia in Wuhan, China: A Descriptive Study. The Lancet Respiratory Disease, 395, 507-513. https://doi.org/10.1016/S0140-6736(20)30211-7

[48] Zhou, F., Yu, T., Du, R., Fan, G., Liu, Y., Liu, Z., Xiang, J., et al. (2020) Clinical 
Course and Risk Factors for Mortality of Adult Inpatients with COVID-19 in Wuhan, China: A Retrospective Cohort Study. The Lancet, 395, 1054-1062.

https://www.thelancet.com/pdfs/journals/thelancet/PIIS0140-6736(20)30566-3.pdf https://doi.org/10.1016/S0140-6736(20)30566-3

[49] Klok, F.A., Kruip, M.J.H.A., van der Meer, N.J.M., Arbous, M.S., Gommers, D.A.M.P.J., Kant, K.M., et al. (2020) Incidence of Thrombotic Complications in Critically Ill ICU Patients with COVID-19. Thrombosis Research, 191.

https://www.thrombosisresearch.com/article/S0049-3848(20)30120-1/pdf https://doi.org/10.1016/j.thromres.2020.04.013

[50] Inamura, N., Miyashita, N., Hasegawa, S., Kato, A., Fukuda, Y., Saitoh, A., Kondo, E., et al. (2014) Management of Refractory Mycoplasma pneumoniae. Utility of Measuring Serum Lactate Dehydrogenase Level. Journal of Infection and Chemotherapy, 20, 270-273. https://doi.org/10.1016/j.jiac.2014.01.001 https://www.sciencedirect.com/science/article/abs/pii/S1341321X14000737

[51] Nesser, O.L., Vukajlovic, T., Felder, L., Haubitz, S., Hammerer-Lercher, A., Ottiger, C., Mueller, B., Schuetz, P. and Fux, C.A. (2019) A High C-Reactive Protein/Procalcitonin Ratio Predicts Mycoplasma pneumoniae Infection. Clinical Chemistry and Laboratory Medicine, 57, 1638-1646.

https://www.degruyter.com/view/journals/cclm/57/10/article-p1638.xml https://www.ncbi.nlm.nih.gov/pubmed/31128571 https://doi.org/10.1515/cclm-2019-0194

[52] Bar Meir, E., Amital, H., Levy, Y., Kneller, A., Bar-Dayan, Y. and Shoenfeld, Y. (2000) Mycoplasma-pneumoniae-Induced Thrombotic Thrombocytopenic Purpura. Acta Haematologica, 103, 112-115. https://doi.org/10.1159/000041030 https://www.karger.com/Article/Abstract/41030

[53] Rathinam, V.A.K. and Fitzgerald, K.A. (2011) Cytosolic Surveillance and Antiviral Immunity. Current Opinion in Virology, 1, 455-462.

https://www.sciencedirect.com/science/article/abs/pii/S1879625711001696 https://doi.org/10.1016/j.coviro.2011.11.004

[54] Totura, A.L. and Baric, R.S. (2012) SARS Coronavirus Pathogenesis: Host Innate Immune Responses and Viral Antagonism of Interferon. Current Opinion in $\mathrm{Vi}$ rology, 2, 264-275. https://doi.org/10.1016/j.coviro.2012.04.004 https://www.sciencedirect.com/science/article/pii/S1879625712000715-bib021054

[55] Cameron, M.J., Ran, L., Xu, L., Danesh, A., Bermejo-Martin, J.F., Cameron, C.M., Nuller, M.P., et al. (2007) Interferon-Mediated Immunopathological Events Are Associated with Atypical Innate and Adaptive Immune Responses in Patients with Severe Acute Respiratory Syndrome. Journal of Virology, 81, 8692-8706.

https://jvi.asm.org/content/81/16/8692 https://doi.org/10.1128/JVI.00527-07

[56] Rottem, S. (2003) Interaction of Mycoplasmas with Host Cells. Physiological Reviews, 83, 417-432. https://doi.org/10.1152/physrev.00030.2002

[57] He, J., Liu, M., Ye, Z., Tan, T., Liu, X., You, X., Zeng, Y. and Wu, Y. (2016) Insights into the Pathogenesis of Mycoplasma penumoniae. Molecular Medicine Reports, 14, 4030-4036. https://www.spandidos-publications.com/mmr/14/5/4030 https://doi.org/10.3892/mmr.2016.5765

[58] Baseman, J.B. and Tully, J.G. (1997) Mycoplasmas: Sophisticated, Reemerging, and Burdened by Their Notoriety. Emerging Infectious Diseases, 3, 21-32. https://www.ncbi.nlm.nih.gov/pmc/articles/PMC2627593/pdf/9126441.pdf https://doi.org/10.3201/eid0301.970103

[59] Minion, F.C., Jarvill-Taylor, K.J., Billings, D.E. and Tigges, E. (1993) Membrane- 
Associated Nuclease Activities in Mycoplasmas. Journal of Bacteriology, 175, 78427847. https://www.ncbi.nlm.nih.gov/pmc/articles/PMC206960 https://doi.org/10.1128/JB.175.24.7842-7847.1993

[60] Saitoh, S., Wada, T., Narita, M., Kohsaka, S., Mizukami, S., Togashi, T. and Kajii, N. (1993) Mycoplasma pneumoniae Infection May Cause Striatal Lesions Leading to Acute Neurologic Dysfunction. Neurology, 43, 2150-2151.

https://doi.org/10.1212/WNL.43.10.2150

[61] Komada, Y., Zhang, X.L., Zhou, Y.W., Ido, M. and Azuma, E. (1997) Apoptotic Cell Death of Human Lymphoblastoid Cells Induced by Arginine Deaminase. International Journal of Hematology, 65, 129-141. https://doi.org/10.1016/S0925-5710(96)00538-5

[62] Nicolson, G.L. (2019) Pathogenic Mycoplasma Infections in Chronic Illnesses: General Considerations in Selecting Conventional and Integrative Treatments. International Journal of Clinical Medicine, 10, 477-522.

https://www.scirp.org/journal/paperinformation.aspx?paperid=95720 https://doi.org/10.4236/ijcm.2019.1010041

[63] Rawadi, G., Roman-Roman, S., Castedo, M., Dutilleul, V., Susin, S., Marchetti, P., Geuskens, M. and Kroemer, G. (1996) Effects of Mycoplasma fermentans on the Myelomonocytic Linage. Different Molecular Endities with Cytokine-Inducing and Cytocidal Potential. Journal of Immunology, 156, 670-678.

https://www.jimmunol.org/content/156/2/670

[64] Waites, K.B., Xiao, L., Liu, Y., Balish, M.F. and Atkinson, T.P. (2017) Mycoplasma pneumonia from the Respiratory Tract and Beyond. Clinical Microbiology Reviews, 30, 747-809. https://doi.org/10.1128/CMR.00114-16

[65] Becker, A., Kannan, T.R., Taylor, A.B., Pakhornova, O.N., Zhang, Y., Somarajan, S.R., Galaleldeen, A., Holloway, S.P., Baseman, J.B. and Hart, P.J. (2015) Structure of CARDS Toxin, a Unique ADP-Ribosylating and Vacuolating Cytotoxin from Mycoplasma pneumoniae. Proceedings of the National Academy of Sciences USA, 112, 5165-5170. https://doi.org/10.1073/pnas.1420308112

[66] Muir, M.T., Cohn, S.M., Louden, C., Kannan, T.R. and Baseman, J.B. (2011) Novel Toxin Assays Implicate Mycoplasma pneumoniae in Prolonged Ventilator Course and Hypoxemia. Chest, 139, 305-310. https://doi.org/10.1378/chest.10-1222 https://journal.chestnet.org/article/S0012-3692(11)60069-X/pdf

[67] Wang, Y., Lu, X., Chen, H., Chen, T., Su, N., Huang, F., Zhou, J., et al. (2020) Clinical Course and Outcomes of 344 Intensive Care Patients with COVID-19. American Journal of Respiratory and Critical Care Medicine. (In Press) https://doi.org/10.1164/rccm.202003-0736LE

[68] Matute-Bello, G., Frevert, C.W. and Martin, T.R. (2008) Animal Models of Acute Lung Injury. American Journal of Physiology-Lung Cellular and Molecular Physiology, 295, L379-L399. https://doi.org/10.1152/ajplung.00010.2008

[69] Teijaro, J.R. (2017) Cytokine Storms in Infectious Diseases. Seminars in Immunopathology, 39, 501-517. https://doi.org/10.1007/s00281-017-0640-2 https://link.springer.com/article/10.1007/s00281-017-0640-2

[70] Tisoncik, J.R., Korth, M.J., Simmons, C.P., Farrar, J., Martin, T.R. and Katze, M.G. (2012) Into the Eye of the Cytokine Storm. Microbiology and Molecular Biology Reviews, 76, 16-32. https://mmbr.asm.org/content/76/1/16 https://doi.org/10.1128/MMBR.05015-11

[71] Nicholls, J., Dong, X.-P., Jang, G. and Peiris, M. (2003) SARS: Clinical Virology and Pathogenesis. Respirology, 8, S6-S8. 
https://doi.org/10.1046/j.1440-1843.2003.00517.x

[72] Yang, J., Hooper, W.C., Phillips, D.J. and Talkington, D.F. (2002) Regulation of Pro-Inflammatory Cytokines in Human Lung Epithelial Cells Infected with Mycoplasma pneumoniae. Infection and Immunity, 70, 3649-3655.

https://iai.asm.org/content/70/7/3649 https://doi.org/10.1128/IAI.70.7.3649-3655.2002

[73] Nicolson, G.L., Nasralla, M.Y. and Nicolson, N.L. (1998) The Pathogenesis and Treatment of Mycoplasmal Infections. Antimicrobics and Infectious Diseases Newsletter, 17, 81-87. https://doi.org/10.1016/S1069-417X(00)88885-8

https://www.sciencedirect.com/journal/antimicrobics-and-infectious-diseasesnewsl etter/vol/17/issue/11

[74] Sauter, P.M., van Rossum, A.M.C. and Vink, C. (2014) Mycoplasma pneumoniae in Children: Carriage, Pathogenesis and Antibiotic Resistance. Current Opinion in Infectious Diseases, 27, 220-227. https://doi.org/10.1097/QCO.0000000000000063 https://journals.lww.com/co-infectiousdiseases/Abstract/2014/06000/Mycoplasma_ pneumoniae_in_children_carriage,.3.aspx

[75] Kenny, G.E. and Cartwright, F.D. (2001) Susceptibilities of Mycoplasma hominis, M. pneumoniae, and Ureaplasma urealyticum to GAR-936, Dalfopristin, Dirithromycin, Evernimicin, Gatifloxacin, Linezolid, Moxifloxacin, Quinupristin-Dalfopristin, and Telithromycin Compared to Their Susceptibilities to Reference Macrolides, Tetracyclines, and Quinolones. Antimicrobial Agents and Chemotherapy, 45, 26042608. https://aac.asm.org/content/45/9/2604 https://doi.org/10.1128/AAC.45.9.2604-2608.2001

[76] Arai, S., Gohara, Y., Kuwano, K. and Kawashima, T. (1992) Antimycoplasmal Activities of New Quinolones, Tetracyclines and Macrolides against Mycoplasma pneumoniae. Antimicrobial Agents and Chemotherapy, 36, 1322-1324.

https://aac.asm.org/content/36/6/1322 https://doi.org/10.1128/AAC.36.6.1322

[77] Renaudin, H. and Bébéar, C. (1990) Comparative in Vitro Activity of Azithromycin, Clarithromycin, Erythromycin and Lomefloxacin against Mycoplasma pneumoniae, Mycoplasma hominis and Ureaplasma urealyticum. European Journal of Clinical Microbiology and Infectious Diseases, 9, 838-841.

https://link.springer.com/article/10.1007/BF01967388 https://doi.org/10.1007/BF01967388

[78] Cao, B., Ren, L.-L., Zhao, R., Gonzalez, R., Song, S.-F., Bai, L., Yin, Y.D., et al. (2010) Viral and Mycoplasma pneumoniae Community-Acquired Pneumonia and Novel Clinical Outcome Evaluation in Ambulatory Adult Patients in China. European Journal of Clinical Microbiology and Infectious Disease, 29, 1443-1448. https://link.springer.com/article/10.1007/s10096-010-1003-2 https://doi.org/10.1007/s10096-010-1003-2

[79] Schögler, A., Kopf, B.S., Edwards, M.R., Johnston, S.L., Casaulta, C, Kleninger, E., Jung, A., Moeller, A., et al. (2015) Novel Antiviral Properties of Azithromycin in Cystic Fibrosis Airway Epithelial Cells. European Respiratory Journal, 45, 428-439. https://erj.ersjournals.com/content/45/2/428 https://doi.org/10.1183/09031936.00102014

[80] Retallack, H., Di Lullo, E., Arias, C., Knopp, K.A., Laurie, M.T. and Sandoval-Espinosa, C. (2016) Zika Virus Cell Tropism in the Developing Human Brain and Inhibition by Azithromycin. Proceedings of the National Academy of Sciences USA, 113, 14408-14413. https://www.ncbi.nlm.nih.gov/pmc/articles/PMC7102549 https://doi.org/10.1073/pnas.1618029113 
[81] Rubin, B.K. and Henke, M.O. (2004) Immunomodulatory Activity and Effectiveness of Macrolides in Chronic Airway Disease. Chest, 125, 70S-78S.

https://www.ncbi.nlm.nih.gov/pubmed/14872003 https://doi.org/10.1378/chest.125.2_suppl.70S

[82] Min, J.-Y. and Jang, Y.J. (2012) Macrolide Therapy in Respiratory Viral Infections. Mediators of Inflammation, 2012, Article ID: 649570.

https://www.hindawi.com/journals/mi/2012/649570

https://doi.org/10.1155/2012/649570

[83] Porter, J.D., Watson, J., Roberts, L.R., Gill, S.K., Groves, H., Dhariwal, J., Almond, M.H., et al. (2016) Indentification of Novel Macrolides with Antibacterial, Anti-Inflammatory and Type I and III INF-Augmenting Activity in Airway Epithelium. Journal of Antimicrobial Chemotherapy, 71, 2767-2781.

https://academic.oup.com/jac/article/71/10/2767/2388101 https://doi.org/10.1093/jac/dkw222

[84] Lu, Z.K., Yuan, J., Li, M., Sutton, S.S., Rao, G.A., Jacob, S. and Bennett, C.L. (2015) Cardiac Risks Associated with Antibiotics: Azithromycin and Levofloxacin. Expert Opinion on Drug Safety, 129, 715-724.

https://www.tandfonline.com/doi/full/10.1517/14740338.2015.989210?scroll=top\&n eedAccess=true https://doi.org/10.1517/14740338.2015.989210

[85] Gautret, P., Lagier, J.-C., Parola, P., Hoang, V.T., Meddeb, L., Mailhe, M., Doudier, B., Courjon, J., et al. (2020) Hydroxychloroquine and Azithromycin as a Treatment of COVID-19: Results of an Open Label Non-Randomized Clinical Trial. International Journal of Antimicrobial Agents, 2020, Article ID: 105949.

https://www.ncbi.nlm.nih.gov/pmc/articles/PMC7102549

https://doi.org/10.1016/j.ijantimicag.2020.105949

[86] Chukwudi, C.U. (2016) rRNA Binding Sites and the Molecular Mechanism of Action of the Tetracyclines. Antimicrobial Agents and Chemotherapy, 60, 4433-4441. https://aac.asm.org/content/aac/60/8/4433.full.pdf https://doi.org/10.1128/AAC.00594-16

[87] Vincent, M.J., Bergeron, E., Benjannet, S., Eirkson, B.R., Rollin, P.E., Ksiazek, T.G., Seidah, N.G. and Nichol, S.T. (2005) Chloroquine Is a Potent Inhibitor of SARS Coronavirus Infections and Spread. Virology Journal, 2, Article No. 69. https://virologyj.biomedcentral.com/articles/10.1186/1743-422X-2-69\#citeas https://doi.org/10.1186/1743-422X-2-69

[88] Lim, H.-S., Im, J.-S., Cho, J.-Y., Bae, K.-S., Klein, T.A., Yeom, J.-S., Kim, T.-S., Choi, J.-C., Jang, I.-J. and Park, J.-W. (2009) Pharmacokinetics of Hydroxychloroquine and Its Clinical Implications in Chemoprophylaxis against Malaria Caused by Plasmodium vivax. Antimicrobial Agents and Chemotherapy, 53, 1468-1475. https://aac.asm.org/content/aac/53/4/1468.full.pdf https://doi.org/10.1128/AAC.00339-08

[89] Titus, E.O. (1989) Recent Developments in the Understanding of the Pharmacokinetics and Mechanism of Action of Chloroquine. Therapeutic Drug Monitoring, 11, 369-379. https://doi.org/10.1097/00007691-198907000-00001 https://journals.lww.com/drug-monitoring/Abstract/1989/07000/Recent_Developm ents_in_the_Understanding_of_the.1.aspx

[90] Schroeder, M.E., Russo, S, Costa C., Hori, J., Tiscornia, I., Bollati-Fogolin, M., Zamboni, D.S., Ferreira, G., Cairoli, E. and Hill, M. (2017) Pro-Inflammatory $\mathrm{Ca}^{++}$-Activated $\mathrm{K}^{+}$Channels Are Inhibited by Hydroxychoroquine. Nature Scientific Reports, 7, Article No. 1892. https://doi.org/10.1038/s41598-017-01836-8 
https://www.nature.com/articles/s41598-017-01836-8-citeas

[91] Gao, J., Tian, Z. and Yang, X. (2020) Breakthrough: Chloroquine Phosphate Has Shown Apparent Efficacy in Treatment of COVID-19 Associated Pneumonia in Clinical Studies. Bioscience Trends, 14, 72-73.

https://doi.org/10.5582/bst.2020.01047

https://www.biosciencetrends.com/article/1883

[92] Borba, M.G.S., Val, F.F.A., Sampaio, V.S., Alexandre, M.A.A., Melo, G.C., Brito, M., Mouräno, M.P.G., Brito-Sousa, J.D., et al. (2020) Effect of High vs Low Doses of Chloroquine Diphosphate as Adjunct Therapy for Patients Hospitalized with Severe Acute Respiratory Syndrome Coronavirus 2 (SARS2CoV-2) Infection: A Randomized Clinical Trial. JAMA Network Open, 3, e208857.

https://jamanetwork.com/journals/jamanetworkopen/fullarticle/2765499 https://doi.org/10.1001/jamanetworkopen.2020.8857

[93] Singh, A.K., Singh, A., Shaikh, A., Singh, R. and Misra, A. (2020) Chloroquine and Hydroxychloroquine in the Treatment of COVID-19 with or without Diabetes: A Systemematic Search and a Narrative Review with a Special Reference to India and Other Developing Countries. Diabetes and Metabolic Syndrome. Clinical Research \& Reviews, 14, 241-246. https://doi.org/10.1016/j.dsx.2020.03.011 https://www.sciencedirect.com/science/article/pii/S1871402120300515

[94] Li, H., Zhou, Y., Zhang, M., Wang, H., Zhao, Q. and Liu, J. (2020) Updated Approaches against SARS-CoV-2. Antimicrobial Agents and Chemotherapy. (In Press) https://aac.asm.org/content/aac/early/2020/03/18/AAC.00483-20.full.pdf https://doi.org/10.1128/AAC.00483-20

[95] Nicolson, G.L., Ferreira de Mattos, G., Settineri, R., Costa, C., Ellithorpe, R., Rosenblatt, S., La Valle, J., Jimmenez, A. and Ohta, S. (2016) Clinical Effects of Hydrogen Administration: From Animal and Human Diseases to Exercise Medicine. International Journal of Clinical Medicine, 7, 32-76. https://doi.org/10.4236/ijcm.2016.71005

[96] Montagnier, L. and Blanchard, A. (1993) Mycoplasmas as Co-Factors in Infection Due to the Human Immunodeficiency Virus. Clinical Infectious Diseases, 17, S309S315. https://www.jstor.org/stable/4457254?seq=1

[97] Blanchard, A. and Montagnier, L. (1994) AIDS Associated Mycoplasmas. Annual Review of Microbiology, 48, 687-712.

https://www.annualreviews.org/doi/pdf/10.1146/annurev.mi.48.100194.00335194 https://doi.org/10.1146/annurev.mi.48.100194.003351

[98] Chakraborty, S. and Das, G. (2020) Secondary Infection by Anaerobic Bacteria Possibly Ensues a Battle for Oxygen in SARS-CoV-2 Infected Patients: Anaerobe-Targeting Antibiotics (Like Doxyclcine/Metronidazole) to Supplement Azithromycin in the Treatment of COVID19? OSF Preprints, April 10. (In Press) https://doi.org/10.31219/osf.io/s48fv

[99] Stricker, R.B. and Fesler, M.C. (2020) A Novel Plan to Deal with SARS-CoV-2 and COVID-19 Disease. Journal of Medical Virology, April 28. (In Press)

https://onlinelibrary.wiley.com/doi/abs/10.1002/jmv.25945

https://doi.org/10.31219/osf.io/urzkd 